\title{
Ultrasound and jaundice
}

\author{
F. R. VICARY, G. CUSICK, I. M. SHIRLEY, AND R. J. BLACKWELL \\ From University College Hospital, London
}

SUMMARY We have examined 26 consecutive jaundiced patients referred to the ultrasound clinic. A differentiation between extrahepatic and other causes of jaundice was possible in 23 of the 24 patients satisfactorily examined. The use of ultrasonic techniques in the jaundiced patient offers a high degree of accuracy to the clinician, and little or no discomfort to the patient.

The ability to differentiate between extrahepatic biliary obstruction and other causes of jaundice is important to the clinician. Extrahepatic obstruction is often amenable to surgically curative or palliative procedures, while an exploratory laparotomy may be hazardous in a patient with hepatitis or cirrhosis (Strack et al., 1971).

Various biochemical parameters have been used to distinguish between obstructive and non-obstructive jaundice. In particular an alkaline phosphatase level of over $30 \mathrm{King}$ Armstrong units is said strongly to suggest biliary obstruction (Sherlock, 1975a). Recently a computer has been used to help in the differential diagnosis of jaundice (Stern et al., 1973). Endoscopic retrograde cannulation of the ampulla of Vater has been used to determine the patency of the biliary system with good results in expert hands (Blumgart et al., 1972).

None of these methods is completely reliable and all of them cause some discomfort to the patient. We wish to report our experience with our first 26 jaundiced patients.

\section{Methods}

\section{PATIENTS}

Twenty-six consecutive patients with jaundice were seen at the clinic. The patients were, in general, referred because the clinician could not decide whether extrahepatic obstruction was or was not present. In three cases, while clinically extrahepatic obstruction seemed likely, the surgical team wished to know whether stones were present or not.

The patients were referred by physicians or surgeons at University College Hospital, the

Received for publication 26 July 1976
Whittington Hospital, or the Hospital for Tropical Diseases.

Patients were all seen in an unfasted state, having had a fat-containing meal up to three hours previously.

\section{TECHNIQUES}

The patients were scanned using the Nuclear Enterprises 4102 Diasonograph without grey-scale or the Unirad (Denver, Colorado) grey-scale scanner.

The abdomen was covered in a layer of arachis oil and scanned using parasagittal sector sweeps, $1 \mathrm{~cm}$ apart, under the ribs in the epigastrium and right hypochondrium (Figs. 1 and 2). Transverse scans from the xiphisternum downwards were also performed, generally at $2 \mathrm{~cm}$ intervals.

Occasionally the patient lay on the left side and the abdomen was scanned below the ribs on the right in a coronal plane to obtain views of the common bile duct.

Scans were reported by the clinician and physicist, who were both present throughout the procedure.

The reports stated (1) the size of the gall-bladder in three planes at right angles to each other; (2) the state of the bile ducts-whether distended or normal; (3) whether stones were seen.

Finally, a conclusion was drawn as to whether extrahepatic obstruction was or was not present.

\section{Results}

Of the 26 patients with jaundice, follow-up was possible in all of them: 18 of the 26 patients seen were scanned with a conventional B-scanner and eight were scanned with a grey-scale machine. In two patients, satisfactory scanning was not possible for technical reasons-that is, gas in the bowel or machine problems. It was possible to differentiate 
correctly between extrahepatic obstruction and other causes of jaundice in 23 of the remaining 24 (Table 1).

Altogether extrahepatic jaundice was correctly diagnosed in nine of 10 patients, and other nonsurgical causes of jaundice were correctly diagnosed in all 14 patients. The size of the gall-bladder was an important factor in helping to differentiate between extrahepatic obstruction and other causes of jaundice in our non-fasted patients. In one patient, however, no. 11 on Table 1, a normal size gall-bladder and common bile duct were seen, but distended intrahepatic radicles were noted. At laparotomy she was found to have a small carcinoma of the gall-bladder, blocking cystic and common hepatic ducts.

Stones were noted in five patients, although correctly diagnosed as causing obstruction in only three of the five. In all of our obstructed patients,
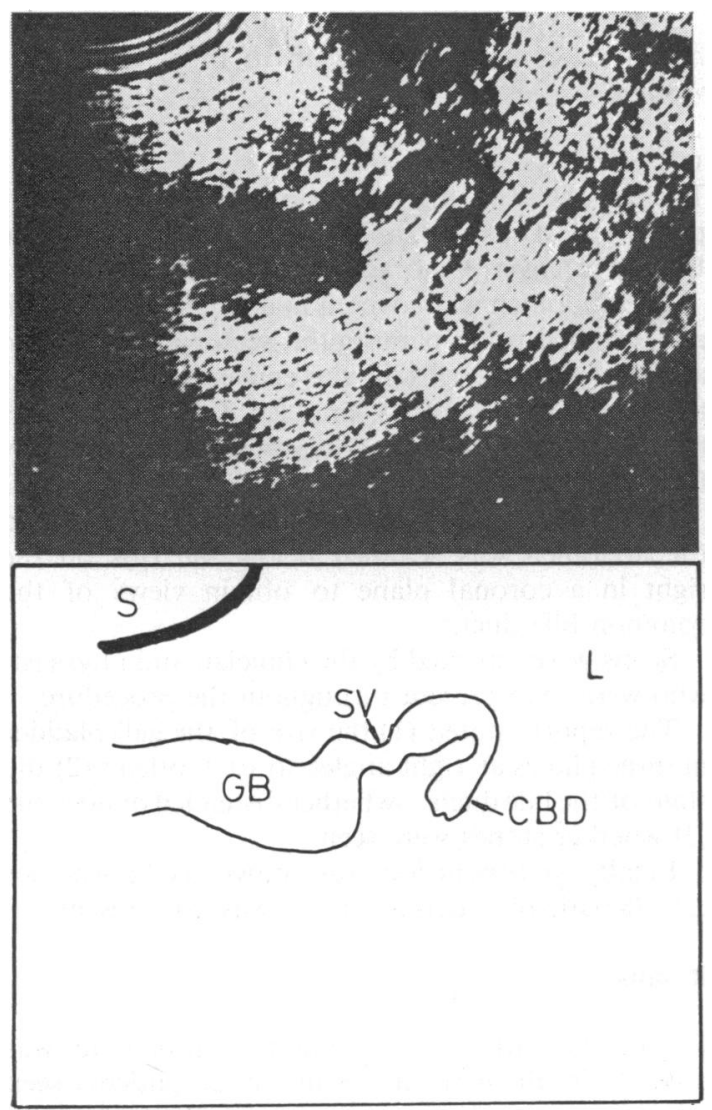

Fig. 1 Parasagittal scan of patient no. 10, showing the gall-bladder $(G B)$, spiral valve $(S V)$ of the cystic duct, and dilated common bile-duct $(C B D)$. The skin $(S)$ and liver $(L)$ are also shown. the gall-bladder volume was computed as more than $60 \mathrm{ml}$. In only one of our patients without gallbladder obstruction was the gall-bladder volume greater than $60 \mathrm{ml}$. Gall-bladder volumes were computed by assuming that its shape was like that of a cylinder. Dilated common bile ducts and extrahepatic biliary ducts were found in most of our obstructed patients. Dilated intrahepatic biliary vessels were also frequently detectable (Fig. 3).

Clinical diagnosis of all obstructed patients was made at laparotomy. Diagnosis of our other patients was made in some cases by liver biopsy. In two cases, the jaundice resolved and was assumed by the clinicians in charge of the cases to be due to acute hepatitis.

Table 2 gives a summary of disease states seen in the 24 patients scanned.

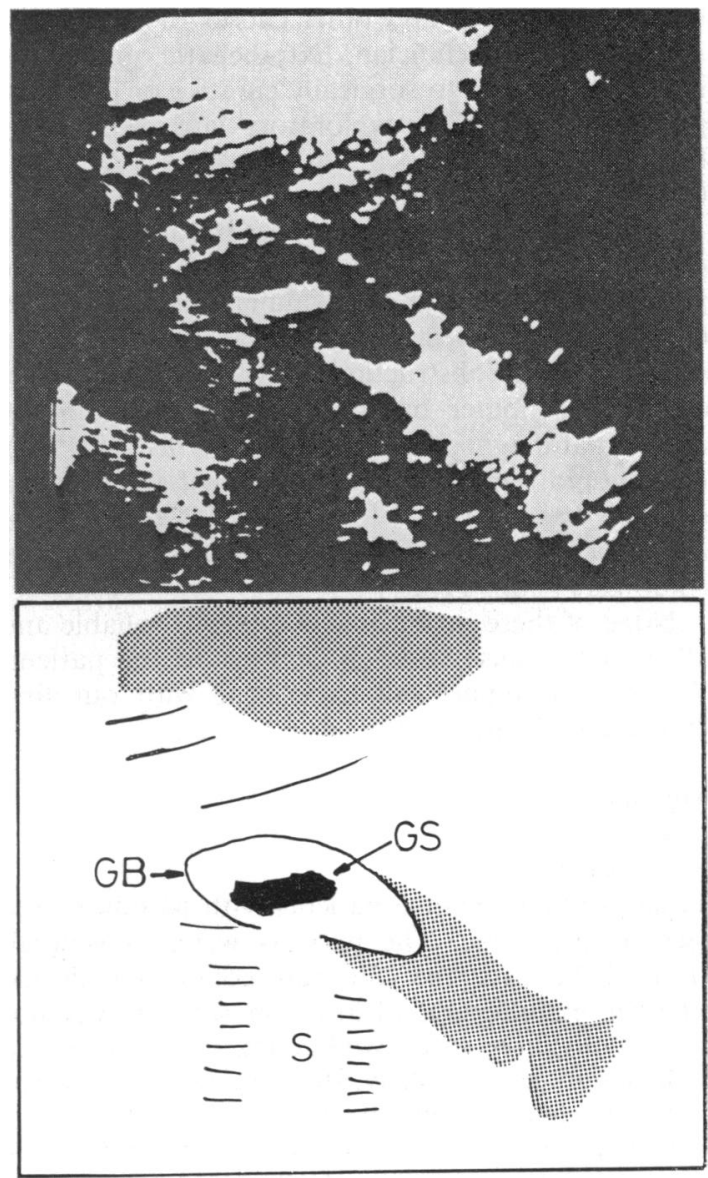

Fig. 2 Parasagittal scan from patient no. 14, showing a large stone $(G S)$ in the gall-bladder $(G B)$. Note the shadow $(S)$ cast by the stone. 
Table 1 Methods of diagnosis

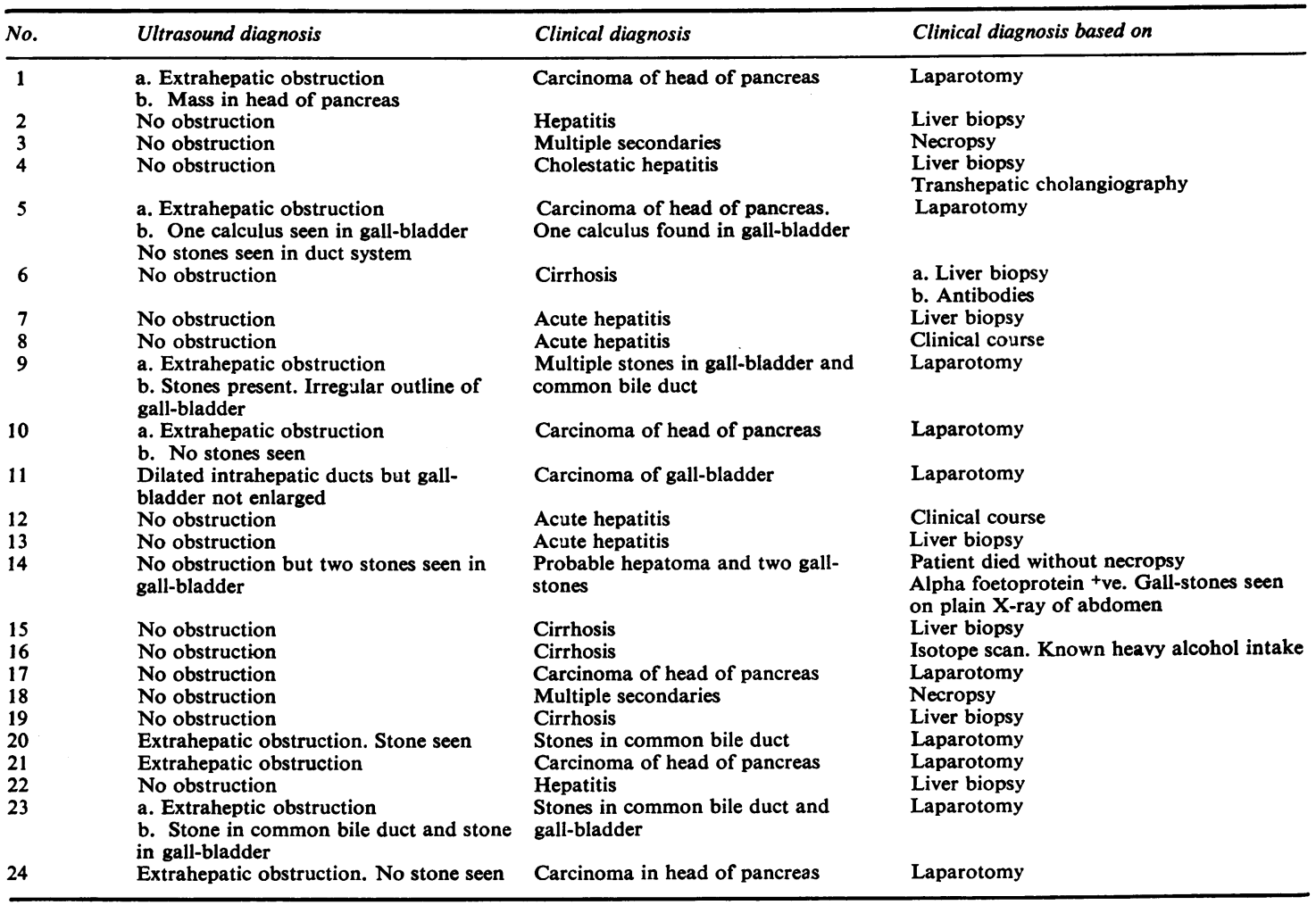

Table 2 Summary of causes of jaundice

\begin{tabular}{lr}
\hline Cause & No. \\
\hline Carcinoma of pancreas & 6 \\
Gall-stones & 3 \\
Carcinoma of gall-bladder & 1 \\
Hepatitis & 7 \\
Cirrhosis & 4 \\
Hepatic tumours & 3 \\
Total & 24 \\
\hline
\end{tabular}

\section{Discussion}

This series demonstrates the value of ultrasound in the differentiation of jaundiced patients into surgical and non-surgical categories. Although we would not claim that ultrasound can provide a complete diagnosis in the jaundiced patient, it is a helpful diagnostic tool. It has the great advantage to the patient of being free from side-effects and completely non-invasive. It, therefore, represents a distinct advance over other diagnostic methods-for example, ERCP-which is unpleasant for the patient and has complications (Kasugai et al., 1972), transhepatic cholangiography which has definite morbidity (George et al., 1965), and liver biopsy which may also be dangerous to the jaundiced patient (Sherlock, 1975b).

We are convinced that it is more rational to scan patients in an unfasted state. In the fasted state the gall-bladder may be distended and may be hard to distinguish from an obstructed gall-bladder. Although we appreciate that there may be sound reasons for examining the gall-bladder in a distended, fasted state in radiological procedures, we suggest that ultrasonic evaluation of the jaundiced patient is simplified by the patient being unfasted.

Although we were able on most occasions to demonstrate the biliary ducts, this was not possible in all patients. It is important to appreciate that the visualisation of a gall stone in the gall-bladder may be an incidental finding, as in two of our patients, and may not be related to the cause of jaundice. We were able to visualise a pancreatic mass in only two of our six patients with proven carcinoma of the 

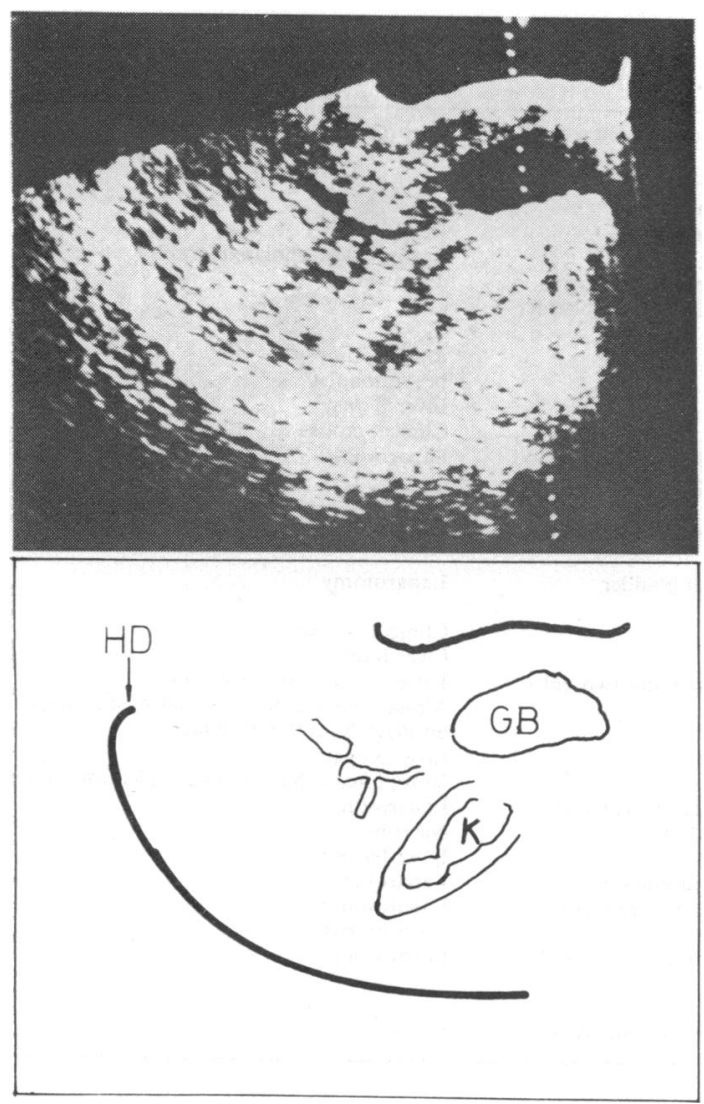

Fig. 3 Showing gall-bladder $(G B)$ with centimetre caliper across, hemidiaphragm (HD), kidney $(K)$, and dilated intrahepatic ducts.

pancreas. Some authors have suggested that visualisation of the pancreas and pancreatic tumours is possible in most cases (Otto et al., 1973), but this is not so in our hands, or in those of Taylor and his colleagues at the Royal Marsden Hospital (Taylor et al., 1974).
Two machines were available to us-one with grey-scale attachments. There was little doubt that grey-scale gave us a clearer indication of organ texture, but we remain unconvinced of its advantage in situations where one is looking for clear-cut ultrasonic boundaries such as those that exist in the biliary system.

\section{References}

Blumgart, L. H., Salmon, P., Cotton, P. B., Davies, G. T., Burwood, R., Beales, J. S. M., Lawrie, B., Skirving, A., and Read, A. E. (1972). Endoscopy and retrograde choledochopancreatography in the diagnosis of the jaundiced patient. Lancet, 2, 1269-1273.

George, P., Young, W. B., Walker, J. G., and Sherlock, S. (1965). The value of percutaneous cholangiography. British Journal of Surgery, 52, 779-783.

Kasugai, T., Kuno, N., Kobayashi, S., and Hattori, K. (1972). Endoscopic pancreatocholangiography. 1. The normal endoscopic pancreatocholangiography. Gastroenterology, 63, 217-234.

Otto, P., Wagner, H. H., and Creutzig, H. (1973). In 2nd World Congress on Ultrasonics in Medicine: Abstracts of Papers (Excerpta Med. Int. Congr. Ser., 277), edited by M. de Vlieger, D. N. White and V. McCready. Excerpta Medica, Amsterdam. American Elsevier, New York.

Sherlock, S. (1975a). Diseases of the Liver and Biliary System, 5th edition, p. 38. Blackwell, Oxford.

Sherlock, S. (1975b). Diseases of the Liver and Biliary System, 5th edition, p. 50. Blackwell, Oxford.

Stern, R. B., Maxwell, J. D., Knill-Jones, R. P., Thompson, R. P. H., and Williams, R. (1973). Use of computerassisted model in diagnosis of drug hypersensitivity jaundice. British Medical Journal, 2, 767-769.

Strack, P. R., Newman, H. K., Lerner, A. G., Green, S. H., Meng, C. H., Del Guercio, L. R. M., and State, D. (1971). An integrated procedure for the rapid diagnosis of biliary obstruction, portal hypertension and liver disease of uncertain etiology. New England Journal of Medicine, 285, $1225-1231$.

Taylor, K. J. W., Carpenter, D. A., and McCready, V. R. (1974). Ultrasound and scintigraphy in the differential diagnosis of obstructive jaundice. Journal of Clinical Ultrasound, 2, 105-116. 